\title{
Adaptive population management advance in its theory and practice
}

\author{
Hiroyuki Matsuda
}

Published online: 8 June 2010

(c) The Society of Population Ecology and Springer 2010

Adaptive management (AM) is a practical process. This special feature includes three articles that introduce practical topics, eradication of exotic species, population management of irrupting wildlife, and international fisheries management.

These population managements share common ideas (Shea et al. 1998). In general, the economic value of total ecosystem service $V(C, N)$ consists of yield of harvest $Y(H)$, cost of harvesting effort $C(E)$, and value of standing biomass $S(N)$, or $V=Y-C+S$, where $N, H$, and $E$ are the standing stock biomass, amount of harvest, and harvesting effort. The yield of harvest is positive in fisheries, and is zero or negative in exotic species and pest animals. In classical fisheries, the value from standing biomass $S(N)$ is usually ignored and seeks to maximize $Y(H)$ (Matsuda et al. 2008). In invasive alien species and pest animals, $S(N)$ is negative. Because of a common mathematical scheme in management of fisheries, wildlife, and exotic species, there is a common property for the optimal solution. Constant escapement is optimal for management of fisheries, exotic species, and probably pest animals, shown by Kotani et al. (2010) in this issue.

Population management procedures for fisheries, wildlife, and invasive species usually face conflict between stakeholders. We expect that the scheme of AM gives a common baseline in scientific knowledge and may help consensus building. In fisheries management of southern bluefin tuna (SBT) by Kurota et al. (2010) in this issue, a pre-agreed set of rules determines how the total allowable catch (TAC) will be adjusted as new monitoring data

H. Matsuda ( $\square)$

Faculty of Environment and Information Sciences, Yokohama National University, Yokohama, Japan e-mail: matsuda@ynu.ac.jp become available. Sophisticated statistical methods including the Bayesian idea is being developed in AM, which fits well to the adaptive learning process of AM. However, in the case of SBT, the management procedure was not implemented because, shortly after its adoption, it became evident that historical catches may have been substantially underreported. The AM takes a variety of uncertainties (measurement error, process uncertainty, and implementation error) into account. Despite this attribute, the AM does not work well if the data are substantially biased by underreporting. Building trust between stakeholders is a key factor of fisheries and wildlife management (Levin 1999).

The feasibility of these management programs definitely depends on cost-effectiveness, described in Kotani et al. (2010) in this issue. They focused on density-dependent catchability, or the ratio of harvest divided by effort and biomass $(H / E / N)$. In Japan, ecologists have some opportunities to give advice on the management of wildlife and exotic species by national or local government as members of scientific councils. They can also give advice on world heritage issues, nature restoration projects, and environmental impact assessments. However, these advisory committees rarely discuss cost and budget. Therefore, these management programs are often not cost-effective. In the early stage of eradication programs, the population density and catch per unit effort (CPUE, defined as $H / E$ ) often rapidly decrease with a high catchability. The proportional relationship between CPUE and the population density is often expected, and it makes the feasibility of eradication program too optimistic. However, it is usually an illusion (Sasaki and Matsuda 2010).

Due to over-harvesting, the sika deer (Cervus nippon) was threatened in Japan from the end of the nineteenth century to the mid-twentieth century. Since the mid- 
twentieth century, deer has been recognized as a pest animal of agriculture and forestry. In Hokkaido prefecture, a deer management program has been established for resource management since 1998 (Kaji et al. 2010, in this issue). Recognition of deer as a pest or a resource is not decided by scientists but by social consensus. Irrespective of whether resource or pest, scientists can construct deer management programs based on the above common scheme.

In AM procedures, the aim and scope is determined by social consensus. Scientists can make a draft action plan and numerical goals to achieve a goal that is agreed by stakeholders and check feasibility of the numerical goals (Rossberg et al. 2005). In the case of the Shiretoko World Heritage site located in northern Japan, the government of Japan rejected the possibility of future fisheries regulations at the heritage site and UNESCO required an increase of the marine conservation level in the heritage site. These seemed to contradict each other. According to a recommendation by the Scientific Council, the local fisheries cooperative association voluntarily expanded the seasonal fishing-ban area in 2005 (Matsuda et al. 2008). The role of scientists is to seek a solution that is agreed by a variety of stakeholders.

Conflicts between stakeholders exist in a variety of international conventions including the Convention on International Trade of Endangered Species (CITES) and the Convention on Biological Diversity. However, the recommendation by scientists who join these conventions may not reflect conflicts between stakeholders. We need to establish a system and work to find solutions that are agreed by stakeholders. A management plan without agreement does not protect any nature.

\section{References}

Kaji K, Saitoh T, Uno H, Matsuda H, Yamamura K (2010) Adaptive management of sika deer populations in Hokkaido, Japan: theory and practice. Popul Ecol. doi:10.1007/s10144-010-0219-4

Kotani K, Kakinaka M, Matsuda H (2010) Adaptive management for eradication of exotic species. Popul Ecol. doi:10.1007/s10144010-0202-0

Kurota H, Hiramatsu K, Takahashi N, Shono H, Itoh T, Tsuji S (2010) Developing a management procedure robust to uncertainty for southern bluefin tuna: a somewhat frustrating struggle to bridge the gap between ideals and reality. Popul Ecol. doi:10.1007/ s10144-010-0201-1

Levin S (1999) Fragile dominion: complexity and the commons. Perseus, Cambridge

Matsuda H, Makino M, Kotani K (2008) Optimal fishing policies that maximize sustainable ecosystem services. In: Tsukamoto K, Kawamura T, Takeuchi T, Beard TD Jr, Kaiser MJ (eds) Fisheries for global welfare and environment, 5th World Fisheries Congress 2008. Terrapub, Tokyo, pp 359-369

Rossberg AG, Matsuda H, Koike F, Amemiya T, Makino M, Morino M, Kubo T, Shimoide S, Nakai S, Katoh M, Shigeoka T, Urano K (2005) A guideline for ecological risk management procedures. Landsc Ecol Eng 1:221-228

Sasaki S, Matsuda H (2010) Trap allocation method for the alien mammals and comparison of the effect of the method. Jpn J Cons Ecol (in press) (in Japanese)

Shea K, Amarasekare P, Kareiva P, Mangel M, Moore J, Murdoch WW, Noonburg E, Parma AM, Pascual MA, Possingham HP, Wilcox C, Yu D (1998) Management of populations in conservation, harvesting and control. Trend Ecol Evol 13:371375 